behavior and general behavior theory

Englewood Cliffs, N.J: Prentice-Hall, 1968.

NOTE

1. Note added in proof: Similar correlational discrepancies have been reported by M. W. L aurance (Age difterences in performance and subjective organization in the free-recall learning of pictorial material. Canadian Journal of Psychology, 1966, 20, 388-399).

\title{
The relationship between self-reported pulse rates and exam scores
}

\author{
ROBERT M. STERN and TRUDY L. BUSH \\ Pennsylvania State University, University Park, Pa. 16802
}

Introductory psychology students took their own pulses during a normal lecture class and during four exams. There was no systematic relationship between absolute pulse rate and exam scores. However, consistently high correlations were found between pulse-rate change scores and test performance: The greater the increase in pulse rate, the lower the exam score.

Until recently the investigation of the relationship of pulse rate to performance on exams was limited to the following two approaches: (1) administering a test to individual $\mathrm{Ss}$ in a laboratory situation so that pulse rates could be continuously measured (e.g., Waite, 1942; Judson \& Gelber, 1965) or (2) obtaining pulse rates immediately before and immediately after a real-life test situation (e.g., Talbert, 1944). Shortcomings inherent in both of the above methods are obvious.

Southard \& Katahn (1967) have recently demonstrated that there is an extremely high correlation between self-reported and

Table 1

Correlations Between Pulse Rate Increase over Resting Level and Perform ance on Introductory Psychology Tests

\begin{tabular}{lccc}
\hline & \multicolumn{3}{c}{ Males $(\mathrm{N}=99)$} \\
\cline { 2 - 4 } & Start & Mid & End \\
\hline EXAM 1 & +.022 & -.143 & .095 \\
EXAM 2 & $-.511^{*}$ & $-.529^{*}$ & $-.341^{*}$ \\
EXAM 3 & $-.598^{*}$ & $-.559^{*}$ & $.508^{*}$ \\
EXAM 4 & $-.508^{*}$ & $-.446^{*}$ & $-.387^{*}$ \\
\hline & \multicolumn{4}{c}{ Females (N =80) } \\
\hline & & Mid & End \\
\hline EXAM 1 & -.116 & -.075 & +.005 \\
EXAM 2 & $.393^{*}$ & -.143 & $-.350^{*}$ \\
EXAM 3 & $-.464^{*}$ & $.217^{*}$ & $-.538^{*}$ \\
EXAM 4 & -.198 & .153 & $-.237^{*}$ \\
\hline * 4 05 & & &
\end{tabular}

${ }_{p}<.05$ mechanically recorded pulse rates. Following from their suggestion, the current authors investigated self-reported pulse rate during normal class periods and during examination periods and related these data to test performance.

$$
\text { METHOD }
$$

The 179 Ss ( 99 males and 80 females) were students in the first author's introductory psychology class.

During a lecture on the autonomic nervous system, Ss were taught to take their own pulses from the radial artery. At the following lecture, with no prior notice, a form was passed out on which each $S$ was to indicate his pulse at the beginning, middle, and end of the period. The $\mathrm{E}$ initiated the measurement sequence 5, 30, and $55 \mathrm{~min}$ after the start of class by saying, "Find your pulse-ready-go"; after $15 \mathrm{sec}$ E would say "stop," and Ss would record their pulse rates. The same data collection procedure was followed during the four exams given in the course.

The test-performance measure used was number of questions correct on 50 -item multiple-choice exams. The class distribution for all four tests was approximately normal.

\section{RESULTS}

Basically, correlations were run separately for males and females and separately for the beginning, middle, and end of each of four exam periods, between pulse rate and test performance.
The first of the two stages of the data analysis failed to reveal any significant correlations. That is, no systematic relationship was found between Ss' absolute pulse rate and their test scores for any of the exams.

The second stage of the analysis involved an investigation of the relationship of relative pulse rate to test scores. The pulse measure used was pulse rate during an exam minus pulse rate for the same part of the period, i.e., beginning, middle, or end, taken during the normal lecture class. Table 1 summarizes the results. The overall finding was that for both males and females, for Exams 2, 3, and 4, the greater the increase in pulse rate over the self-report obtained during the basal day, the poorer the test performance. This relationship was found to be stronger for the males (nine out of nine correlations were significant) than for the females (six out of nine were significant). One additional finding was that neither males nor females showed any systematic relationship between their relative pulse rate and their test scores on Exam 1.

\section{DISCUSSION}

This study is thought to be of interest both because of the specific relationship reported here and because of the demonstration that pulse rate, a commonly used measure of anxiety, can be studied in real-life group situations with no equipment.

The interpretation of the significant negative correlation between increase in pulse rate and test scores is beyond the scope of this preliminary study. One possible explanation is that Ss who were unprepared for the exams looked at the exam, became anxious in anticipation of failing, and therefore displayed a large increase in pulse rate. A second possible explanation is that test anxiety, as manifested in a large increase in pulse rate, interferred with maximal test performance. The fact that this relationship did not appear until the second exam suggests that the latter explanation may better account for this correlational finding.

\section{REFERENCES}

JUDSON, A. J., \& GELBER, G. Test anxiety, pulse rate and learning. Psychonomic Science, 1965, 3, 397-398.

SOUTHARD, L. D. \& KATAHN, M. The correlation between self-reported and mechanically-recorded pulse rates. Psychonomic Science, 1967, 8, 343-344.

TALBERT, G. A. Emotional effects of oral examinations upon blood pressure and pulse rate. Proceedings of the Federation of American Societies for Experimental Biology, 1944, 3, 47. (Abstract)

WAITE, $W$. $H$. The relationship between performance on examinations and emotional responses. Journal of Experimental Education, $1942,11.88-96$. 